\title{
El agua y la inmortalidad poética en las églogas de Garcilaso de la Vega

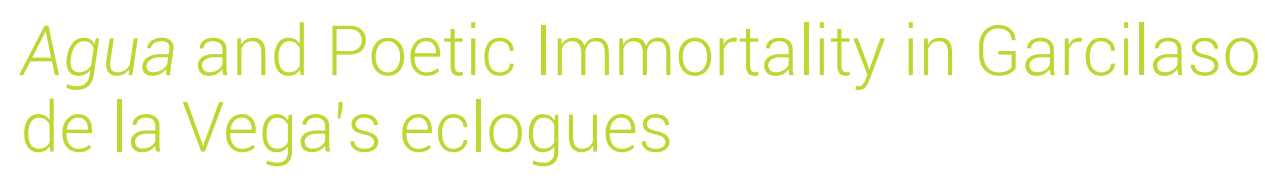

\section{Elizabeth Gansen}

Grand Valley State University

Modern Languages and Literatures

ESTADOS UNIDOS

gansenel@gvsu.edu

[Hipogrifo, (issn: 2328-1308), 8.1, 2020, pp. 411-424]

Recibido: 11-06-2019 / Aceptado: 12-07-2019

DOI: http://dx.doi.org/10.13035/H.2020.08.01.28

Resumen. Este artículo explora el papel protagónico del agua en las tres églogas de Garcilaso de la Vega. Además de dar unidad narrativa a esta serie de poemas, en gran medida este elemento determina el destino de los pastores que habitan en su ribera. Mientras Salicio y Albanio mantienen relaciones conflictivas con el agua que les impiden liberarse de los confines del espacio pastoril y de su condición humana, Nemoroso consigue transcender los límites del mundo humano del locus amoenus para conseguir la inmortalidad poética.

Palabras clave. Agua; río; fuente; locus amoenus; Orfeo; églogas; Tajo; Albanio; Salicio; Nemoroso.

Abstract. This article explores the role of water as a protagonist of Garcilaso de la Vega's three eclogues. In addition to providing this series of poems with a sense of narrative unity, in large part it is the water that determines the destiny of the pastors who inhabit the locus amoenus. While Salicio and Albanio maintain conflicted relationships with the water, preventing them from being able to liberate their poetic verses from the pastoral space and their human condition, Nemoroso is able to transcend these limitations to achieve poetic immorality.

Keywords. Water; River; Fountain; locus amoenus; Orpheus; Eclogue; Garcilaso de la Vega; Tajo; Albanio; Salicio; Nemoroso. 
El agua juega un papel decisivo en las Églogas de Garcilaso de la Vega (15011536). Su presencia se deja sentir al abrir y cerrar esta serie de poemas, y sirve como el marco dentro del cual se llevan a cabo las acciones de los pastores que habitan el locus amoenus. A pesar de tomar como modelo el espacio pastoril en las obras italianas y clásicas de Sannazaro y Virgilio, entre otros, Garcilaso no imita ciegamente su representación en estas lecturas, sino que la transforma'; así pues, el agua se convierte de un simple fondo ornamental de la vida pastoril en un ente con una función narrativa propia².

La importancia de la imagen del agua dentro del locus amoenus no ha pasado desapercibida por los críticos literarios, quienes han señalado su papel unificador como elemento estético y poético propio de la literatura pastoril ${ }^{3}$. No obstante, la mayoría de estos estudios se han limitado a analizar tan solo una égloga, en la cual la representación del agua es uno más de los diversos temas que se han considerado. Por el contrario, este artículo propone dilucidar el papel que desempeña el agua dentro del locus amoenus al considerar las transformaciones que se suceden en su función narrativa que discurre por este corpus poético. El agua no solamente sirve como el foco principal de las acciones que ocurren dentro del espacio pastoril, sino que también opera a un nivel metapoético, como un hilo narrativo que conecta los distintos episodios amorosos de los tres pastores ${ }^{4}$. Tal y como estos personajes van evolucionando a lo largo de las tres églogas, la identidad del agua va cambiando también, tanto en su función biológica como en su sentido poético. Nunca deja de ser el testigo discreto que acompaña a los pastores por sus vaivenes emocionales, pero progresivamente va desprendiéndose del sitio poético del locus amoenus para asumir una identidad dentro de un entorno geográfico y mítico más amplio. De esta manera, el agua adquiere diversas facetas en las églogas de Garcilaso, funcionando de forma simultánea como un ente retórico propio de la poesía pastoril, un fenómeno biológico tanto real como metafórico de origen, y, por último, el umbral a una vida mítica de inmortalidad artística.

1. Ernest Robert Curtius define las descripciones del locus amoenus en la poesía de Teócrito y Virgilio como «merely backgrounds for the ensuing pastoral poetry» (1983, p. 195). Por su parte, Guillermo Araya hace una comparación entre la fuente en la historia de Albanio de la Égloga II y la de L'Arcadia de Sannazaro. Concluye que la presentación de Sannazaro de este elemento es conceptual, mientras que la de Garcilaso es más «intuitiva... y real» (1970, p. 117). Estos modelos poéticos representan la tradición poética que Garcilaso intenta imitar y a la vez superar en la creación del espacio pastoril dentro de las églogas.

2. Araya, 1970, p. 114

3. Ver, por ejemplo, Arce de Vázquez, 1953; MacDonald, 1974 y Rivers, 1974.

4. El agua está presente fuera del locus amoenus también, sobre todo en la historia del Duque de Alba en la Égloga II. Ángel García Galiano ha comentado la función retórica del agua como un espejo que permite el salto del «espacio atemporal del arte» del locus amoenus a la realidad histórica y la transformación de Albanio en la figura del duque (2000, pp. 19-20). Del mismo modo, Guillermo Araya caracteriza el Tormes como un «pórtico de entrada» al relato del duque (1970, p. 125). A pesar de las posibilidades que presenta el agua en relación a estos otros espacios narrativos, el propósito de este artículo es analizar el papel que juega exclusivamente dentro del mundo pastoril, ya que es este espacio el que sirve como el marco principal de las églogas. 
A medida que el agua va transformándose, se reafirma su presencia protagónica en la vida de los pastores, hasta tal punto que determina el destino de cada uno. A pesar de que tanto Salicio y Albanio como Nemoroso declaman sus lamentos amorosos, solo este último logrará que su voz poética transcienda su condición humana y el olvido que acompaña la muerte. Su poder órfico sobre la naturaleza circundante permite que su canción sobre la pérdida de su amada Elisa llegue a los oídos de la ninfa acuática Nise, que hace de su historia un mito nuevo. En cambio, por más que Salicio y Albanio se figuren con los mismos poderes órficos, fracasan en sus esfuerzos por seducir con su canto. En estas negociaciones de los pastores con el mundo que les rodea, será el agua el último árbitro que decida su destino, tanto en cuestiones de la vida como de la muerte.

\section{EL AGUA Y LA VIDA BIOLÓGICA Y POÉTICA DE LA ÉGLOGA I}

No en vano Margot Arce de Vázquez nombra a Garcilaso el primer poeta español que aprecia el paisaje por «su valor propio, como objeto digno de contemplación y de elaboración artística» ${ }^{5}$. Sin embargo, más que ser un simple ornamento estético, el agua es un elemento retórico necesario al locus amoenus y a las acciones que tienen lugar dentro de él. Su rol fundamental en la visión poética de Garcilaso se pone de relieve desde los primeros versos de la Égloga I, en los cuales se establece como el origen de toda vida natural, desde la «alta haya, en la verdura» (v. 466) donde descansa Salicio hasta el sol mismo, que «saliendo de las olas encendido, rayaba de los montes el altura» (vv. 43-44). Al ser el agua el marco desde el cual se puede contemplar la naturaleza, tanto terrenal como del cielo, se convierte en el epicentro de este mundo. En este sentido, el agua ejerce un papel mayor que el de proveedora de vida dentro del locus amoenus, ya que también sus ondas le confieren forma a ella.

Además de servir como raíz de los demás fenómenos naturales a su alrededor, el agua da pie a las quejas amorosas de Salicio al verse repudiado por Galatea. En la orilla, el pastor suelta su «canto acordado / al rumor que sonaba / del agua que pasaba» (vv. 49-51). Este «agua clara con sonido» desempeña un papel interlocutor que dialoga con el pastor, proporcionando el fondo rítmico de sus lamentaciones (vv. 47) ${ }^{7}$. Es decir, más que acompañar al pastor de manera silenciosa, el agua moldea su canción: pese al dolor que siente el pastor, sus quejas son dulces y blandas conforme al discurrir del agua. A través de su murmullo apacible se deja entrever el protagonismo del agua en el locus amoenus, siendo la fuente tanto de la vida biológica como de la poética8. Este vínculo entre el agua y el mundo circundante se desarrollará en profundidad a lo largo de las tres églogas, donde cada vez más

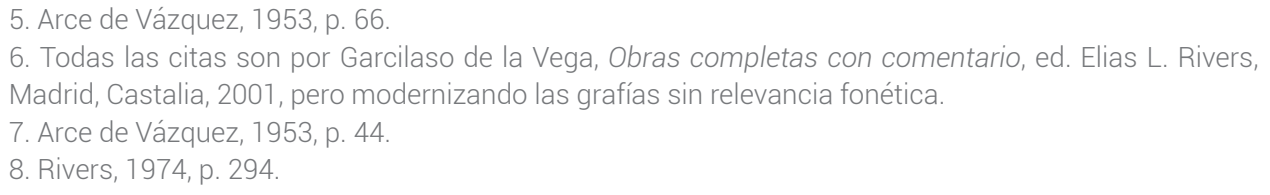


se evidenciará como una fuerza decisiva en las fortunas de los tres pastores que habitan la ribera.

Desde el principio, la relación que mantiene Salicio con el agua está plagada de incertidumbre y tensiones. Si bien consigue ajustar el ritmo de su lamento amoroso con el fluir del agua que pasa a su lado, su estado emocional no concuerda con la paz y tranquilidad del locus amoenus. El desequilibrio que afecta a este pastor y su entorno pastoril anticipa la crisis nerviosa de Albanio que se da en la Égloga II, a la vez que establece un paralelo entre las circunstancias de estos dos pastores y los tenues lazos que los unen a su acompañante acuático. La primera señal de esta ruptura surge de la pesadilla recurrente de Salicio, en la cual está llevando su ganado al río Tajo. Una vez allí, descubre que

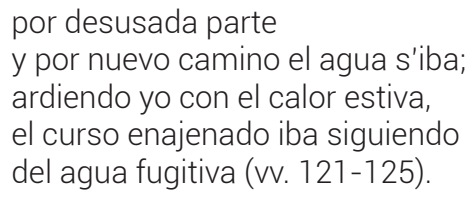

Aunque en ese instante Salicio descarta el sueño como «desvarío», de forma retrospectiva le atribuye una función de augurio: tal y como el río desafía su curso natural al cambiar de lecho, así Galatea le ha abandonado a él por otro (v. 114). Al establecer una correspondencia entre el curso enajenado del agua en su sueño y el declive de su vida amorosa, se resquebraja inevitablemente la relación entre Salicio y el mundo externo del locus amoenus. Puesto que se ha hecho realidad lo inimaginable -el ser descartado por su amante-, todas las leyes que gobernaban el universo del pastor, que consideraba fijas e inmutables, se han subvertido ${ }^{9}$. No sabe en qué confiar ni en qué creer; en su desesperación imagina un futuro dudoso, sin ningún tipo de seguridad: «¿Qué no s'esperará d'aquí adelante, / por difícil que sea y por incierto, / o qué discordia no será juntada?» (vv. 141-143). Los recientes acontecimientos ocurridos en su vida amorosa han puesto en duda todas sus verdades anteriores: ya no posee la certidumbre de poder permanecer siempre con su amada, ni siquiera tiene la certeza de nada, ni de la presencia fija del agua que corre por su lado ni del verdor del bosque.

La poca seguridad que el mundo fuera de sí le ofrece a Salicio en su estado de desespero y confusión hace que este busque recomponerse en las claras aguas del locus amoenus ante la partida de Galatea. Mirándose en la superficie tranquila del agua, Salicio evalúa su apariencia externa, concluyendo:

No soy, pues, bien mirado,

tan disforme ni feo,

que aun agora me veo

en esta agua que corre clara y pura,

9. Parker, 1974, p. 202. 
y cierto no trocara mi figura

con ese que de mí s'está reyendo;

¡trocara mi ventura! (vv. 175-181).

En estos versos, el agua asume el papel de espejo, devolviéndole una imagen de su ser físico y asegurándole al pastor que no hay nada que envidiar al nuevo amante de Galatea salvo los vaivenes de la fortuna. En verdad, Salicio se ve reflejado en el agua para reafirmar su identidad y dar sentido a su realidad. De hecho, a partir de este momento la existencia misma de Salicio se conecta inexorablemente con el espacio del locus amoenus; en la última estrofa de su cantar, el pastor hace hincapié en este lugar como escenario tanto de su pasado amoroso como de su presente triste al repetir tres veces la palabra «aquí» (vv. 216-218). Todas sus acciones se ciñen a este entorno pastoril y, sobre todo, al agua: así como nutre el prado verde, también da sosiego al espíritu atormentado del pastor a su lado, que encuentra en sus claras olas reafirmación y respaldo.

Al mismo tiempo que el agua le sirve a Salicio de espejo y de base poética para su canto, el resto del mundo natural, compadecido, escucha su llanto en el locus amoenus. Como el pastor afirma,

Con mi llorar las piedras enternecen

su natural dureza y la quebrantan;

los árboles parece que s'inclinan:

las aves que m'escuchan, cuando cantan,

con diferente voz se condolecen

[...]

tú sola contra mí t'endureciste,

los ojos aun siquiera no volviendo

a los que tú hiciste (vv. 197-209).

A pesar de que Salicio se imagina como un Orfeo, capaz de enternecer a la naturaleza circundante con sus lamentos, no llega a las alturas del vate griego: si bien las piedras, los árboles y las aves sienten pena por él, no logra ni siquiera que su canto ablande el corazón de Galatea. De hecho, lejos de cautivar a todo ser vivo - humano o divino- con su canto, solo consigue ser escuchado dentro del locus amoenus donde la dulce Filomena le responde (vv. 231-234). El fracaso de sus esfuerzos poéticos hace hincapié en la atención dada al canto de Nemoroso en la misma égloga. En cuanto empieza la historia de este pastor, la voz poética pide auxilio de las musas, ya que se siente incapaz de poner sus penas en verso con su «débil canto» (v. 238). Desde el inicio, al canto de Nemoroso se le otorga una importancia por encima de los lamentos de Salicio por ser material merecedor de las musas mismas y no de simples voces humanas. Por el contrario, las palabras de Salicio, y las de Albanio más tarde, al no ser juzgadas dignas de estas figuras divinas, se quedarán para siempre en boca humana.

El distinto tratamiento poético que recibe el canto de Nemoroso en la Égloga I coincide con las diferentes circunstancias amorosas de cada pastor. La decepción que Salicio experimenta a causa de Galatea lo lleva a acudir al agua para buscar 
sentido a su vida; a pesar de que le promete a su amante que dejará este espacio pastoril por si ella quiere volver al lugar que tanto amaba, su apariencia en la Égloga II indica que no ha cumplido esta promesa (vv. 211-215). En realidad, sería incapaz de hacerlo: lugar de sus recuerdos y amparo emocional de su presente, su existencia está tan unida al locus amoenus que no podría concebir otra realidad que no fuera esta. En contraste, lo único que hace el pastor Nemoroso es soñar con salir de este espacio y liberarse de su condición humana. No necesita el agua para reafirmar su ser, ni busca ningún tipo de refugio en el mundo que le rodea. Más bien desea lo contrario: romper los lazos que lo amarran al locus amoenus para unirse con su «divina Elisa» en la «tercera rueda» (vv. 400). Ruega a su amante que busquen «otro llano [...] otros montes y otros ríos, / otros valles floridos y sombríos» en la esfera espiritual donde puedan pasearse mano a mano (vv. 402-404). Anne J. Cruz identifica este lugar como la esfera de Venus, una «destinación tradicional de las almas de los poetas amatorios» y concluye que la ascensión anhelada por Nemoroso allí puede «interpretarse simultáneamente como un intento por parte de Garcilaso de suplantar el cielo cristiano por un ámbito esencialmente artístico» ${ }^{10}$. A diferencia de Salicio, cuya historia de amor no correspondido le obliga a mirar el mundo concreto y tangible para recuperar la confianza en sí mismo, para Nemoroso el locus amoenus representa únicamente un puente hacia un plano neoplatónico donde puede estar con Elisa y celebrar su $\mathrm{mmor}^{11}$. Será el agua la que posibilite la ascensión de su canto a esta esfera poética.

\section{LA FUENTE Y LA GEOGRAFÍA LITERAL Y POÉTICA DE LA ÉGLOGA ॥}

Si bien en la Égloga I se hace hincapié en el papel protagónico del agua en el entorno del locus amoenus como raíz de la vida natural y poética además de ser sustento emocional humano, en la Égloga II poco a poco empieza a asumir una identidad que transciende los límites geográficos y metafóricos del locus amoenus. Donde primero se percibe este cambio es en el lenguaje que utilizan los pastores para comentar la presencia del agua dentro de este espacio: en los primeros versos del poema, Albanio introduce la palabra «fuente» (v. 2) para referirse a la salida del agua al prado, de igual forma Salicio habla del agua que «la clara fuente envía» (v. 66). La falta de alusión a tal fuente en la primera égloga y su repentina apariencia aquí, en la segunda, indica la necesidad de reevaluar la función retórica del agua a partir de esta égloga. La definición de fuente ofrecida por Sebastián de Covarrubias Orozco en su Tesoro de la lengua castellana o española (1611) supone un punto de partida para indagar esta cuestión. Covarrubias define este término de la siguiente manera:

[el] origen y principio de ríos, alejándose a su corriente las de otros manantiales, por alusión decimos acudir a la fuente cuando recurrimos al principio de lo que vamos tratando y averiguando, y este se llama por otro nombre origen. 
El doble significado geográfico y retórico que Covarrubias destaca en el uso de esta palabra está en juego en la Égloga II. Con respecto al primero, la palabra «fuente» subraya el significado del agua dentro del locus amoenus como el origen del río Tajo. Aunque otros críticos literarios han comentado la presencia de este río en las églogas segunda y tercera, se ha pasado por alto la transformación del elemento acuático que da lugar a su figura, además de sus consecuencias poéticas ${ }^{12}$. Al concebir el agua como fuente, en efecto se redefine el espacio pastoril dentro de un mundo mayor. En consecuencia, la fuente se torna una presencia real en este lugar sumamente pastoril ${ }^{13}$. A medida que se da voz a una realidad fuera del ámbito restringido de las vidas y los amores de los pastores, se les asigna a ellos una identidad correspondiente en la forma de un epíteto nuevo: «vosotros, los del Tajo» (v. 528). El uso del término «fuente» también alude a la capacidad retórica del agua como origen narrativo. Si bien ejercía ya esta función desde los primeros versos de la Égloga I, cobra aquí un sentido más profundo en relación a su nueva identidad como cuerpo de agua mayor. Así pues, se irá convirtiendo en un hilo conductor literal y simbólico que recoge las voces poéticas de Nemoroso y Garcilaso para llevarlas en sus corrientes hacia la inmortalidad artística.

La consciencia sobre un mundo mayor que infunde la Égloga II tiene consecuencias directas en la relación de Albanio y Nemoroso con su entorno pastoril. A diferencia de Salicio, que no consigue imaginar otra realidad que la del locus amoenus, Albanio sueña con un futuro en el que sus versos alcancen una fama inmortal. En sus esfuerzos por transcender los límites de su condición humana, las tensiones que marcan las interacciones de Salicio con el agua ceden paso a una ruptura completa de Albanio con ella. Al igual que Salicio, Albanio fracasa en sus intentos de concebirse como un Orfeo moderno; su historia de amor no correspondido no consigue enternecer al agua ni hacerse escuchar más allá del locus amoenus. En cambio, si en la primera égloga Nemoroso anhela verse reunido con su amada Elisa en un mundo divino, en la Égloga II logra un dominio sobre la palabra que le permite salir del mundo cerrado del locus amoenus y acceder a un conocimiento del mundo natural y humano prohibido a los otros pastores. En ambos casos, es el agua la última mediadora en las cuestiones que determinarán el porvenir de los pastores a su lado.

Según Guillermo Araya, el destino de Albanio «está asociado [...] indisolublemente a la fuente», siendo esta la imagen con la que abre y cierra su historia amorosa, y la que sirve para darle unidad ${ }^{14}$. A pesar de su constante presencia en la realidad de este pastor, su relación con este elemento del locus amoenus está plagada de tensiones y ambigüedades. De acuerdo a lo que Albanio le cuenta a Salicio, el dolor profundo que siente por el desprecio de Camila y la necesidad de desahogar sus penas lo llevan a subir un barranco «de muy gran altura» desde donde contempla el agua, sus olas lamiendo el barranco y erosionando la tierra (v. 541). Al ascender al precipicio, Albanio intenta alejarse del lugar donde habitan sus tristezas y al mismo

12. Ver, por ejemplo, Araya, 1970, Rivers, 1974 y Gallagher, 1980.

13. García Galiano, 2000, p. 24.

14. Araya, 1970, p. 118. 
tiempo transcender sus limitaciones humanas. Su ubicación espacial por encima del agua subraya una diferencia fundamental entre Salicio y Albanio: si el primero se queda dentro del locus amoenus, buscando sosiego en el murmullo del agua que acompaña sus lamentos, Albanio rehúsa este tipo de amparo. Su propósito en dirigirse al agua es otro: a punto de suicidarse, busca confirmación de que su historia amorosa perdure en el mundo de los vivos después de su muerte. Desde la barranca, pide a las ninfas del agua:

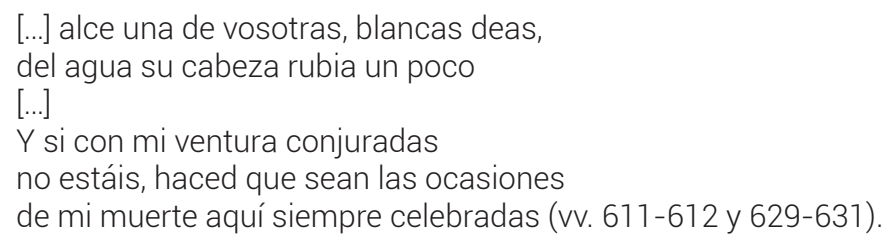

En la súplica de Albanio hay un cambio perceptible en la imagen del agua: mientras que Salicio acude a su superficie clara y tranquila, Albanio se dirige a una presencia nueva debajo de sus ondas -es decir, las náyades. De esta manera, al mismo tiempo que el espacio del locus amoenus se abre a un paisaje más extenso por el cual corre el río Tajo, este ente acuático viene a asumir rasgos míticos. Así como el agua en la primera égloga es más que un simple elemento estético del entorno pastoril, estas ninfas no se limitan a ser un simple ornamento literario ${ }^{15}$. De la misma manera que Albanio trata de que su historia sea siempre recordada al pedir la intervención de ellas, son las ninfas del agua las que tienen el poder de inmortalizar los acontecimientos humanos. Desafortunadamente, Albanio no consigue cautivar la atención de las ninfas y tan solo Eco responde a sus quejas (v. 599)16.

Este episodio presagia el fracaso del segundo y último intento de Albanio por transcender las limitaciones de su mortalidad. Ya enloquecido por la huida de Camila, observa su imagen en el agua del Tajo, haciéndose eco de las acciones de Salicio en la Égloga I. En este caso, sin embargo, Albanio está convencido de que no es su reflejo lo que ve en la superficie del agua sino su cuerpo mismo, atrapado debajo de las ondas. Para liberar a este mancebo de su cautiverio acuático le promete lo siguiente:

15. Ignacio Navarrete estudia la presencia de estas ninfas en el soneto «Hermosas ninfas» de Garcilaso. Concluye diciendo que en este poema la mitología no juega un papel como mero adorno poético, sino que forma una parte integral de la existencia. Así, el poeta español indica que pertenece al mismo mundo de las ninfas, posibilitando su entrada en una esfera de inmortalidad artística (Navarrete, 1994, p. 101). Veremos que las ninfas tienen una función parecida en las églogas.

16. Isabel Torres señala las consecuencias negativas de la intervención de Eco en la historia amorosa de Albanio, argumentando que «the correlation of Albanio's voice with that of Echo, who functions both as a 'symbolically translated Narcissus' and the aural equivalent of the text's deceptive mirror symbolism, strips the speaking voice of the materiality that would give it meaning» $(2009$, p. 883). Lejos de volverse una fuerza dominante a través de su canto, la división del ser de Albanio provocada por su enloquecimiento resulta en una pérdida de autoridad sobre sí mismo y sobre su narrativa (p. 881). 


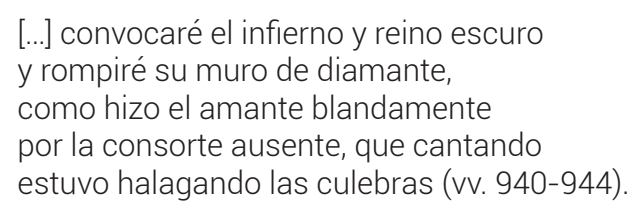

Albanio se imagina con los poderes de Orfeo de conmover con su canto y así emancipar su cuerpo del agua ${ }^{17}$. En este caso, sin embargo, no son las puertas de Hades por las cuales tiene que cruzar, ni siquiera hay un mar inmenso ni montañas altas que lo separen de su otra mitad, sino sencillamente «un poco de agua clara» (v. 962). Por más que Albanio trate de convencerse de la insignificancia de esta barrera acuática, resulta ser insuperable. El pastor se vuelve un Orfeo fracasado, incapaz de ejercer el poder poético del canto que haría que fuera obedecido por la naturaleza circundante. Sus intentos por hacerse escuchar producen un ciclo sin fin -las palabras que lanza desde la barranca y que recoge Eco tienen su equivalente en el agua que le devuelve su propio reflejo. Así, lejos de superar los límites de su condición humana, vive sometido a las exigencias de fuerzas externas que no permiten que ni él ni sus palabras salgan del locus amoenus. La cárcel acuática en la que está atrapado su cuerpo reproduce, a menor escala, la misma incapacidad de Albanio de liberarse de este espacio pastoril por medio de su voz poética.

La falta de dominio que Albanio tiene sobre el mundo que lo rodea, y incluso sobre su ser mismo, pone en primer plano los poderes órficos del pastor Nemoroso en la segunda mitad de la Égloga II. Mientras que las acciones y las identidades de Albanio y Salicio quedan ancladas y circunscritas por el locus amoneus, Nemoroso posee la agencia necesaria para entrar en otros espacios poéticos de las églogas. El pastor cuenta la relación que establece con Severo, un mago capaz de frenar el curso de los ríos y el soplar de los vientos, convertir la tempestad en día claro, controlar el amanecer y la puesta de sol, y hasta enternecer a las piedras con su canto (vv. 1077-1100). Severo trata a Nemoroso como un discípulo suyo, mostrándole los secretos del pasado, presente y porvenir que el río Tormes le reveló a él tallados en una urna (vv. 1172-1176). El conocimiento total que la urna proporciona a Severo, y de forma indirecta a Nemoroso, contrasta con la visión limitada de Salicio y Albanio, para quienes el agua sirve únicamente como fuente de recuerdos. A diferencia de estos, quienes fracasan en sus intentos de ejercer control sobre el agua, la amistad de Nemoroso con Severo le permite al pastor acceder a las herramientas necesarias para saber y entender los procesos históricos y naturales.

A partir de este momento, los rasgos órficos de Nemoroso que se dejan percibir en la primera égloga encuentran una mayor expresión. De la misma manera que Albanio se dirige a las ninfas del agua con la esperanza de hacer inmortal su historia con Camila, Nemoroso también les pide auxilio a la hora de poner en verso su encuentro con Severo. Les suplica, junto con los otros seres míticos que pueblan el locus amoenus, que suelten «[su] lengua en dulces modos y sotiles, / que ni los pastoriles ni el avena / ni la zampoña suena como [quiere]» (vv. 1158-1160). Su 
súplica evoca el mismo ruego hecho por la voz poética en la primera égloga, donde recurre a las musas para dar voz a la historia amorosa de este pastor. No obstante, esta vez es Nemoroso mismo quien insiste en que la fuente de su poesía sea de inspiración divina y no humana. En contraste con las súplicas de Salicio y Albanio, que caen en oídos sordos, la de Nemoroso no es en vano: se le otorga al canto de este pastor la capacidad de hechizar. El entusiasmo de Salicio por escucharle recalca sus poderes órficos: "[i]qqué cosa / puede ser tan sabrosa en otra parte / a mí como escucharte?» (vv. 1140-1142). Este dominio sobre la palabra se lo ha proporcionado el agua misma, ya que a través de la figura de Severo le ha dado la clave del saber. Su canto sobre su amor por Elisa y la pérdida de ella merece más que la sencilla voz humana -es digno de la poesía más divina.

\section{El AGUA COMO VÍA PARA LA LIBERACIÓN POÉTICA EN LA ÉGLOGA III}

Como bien ha señalado Darío Fernández-Morera, desde los primeros versos de la Égloga III la presencia predominante del agua la hace protagonista del poema, dentro del cual es «the element to which almost everything else is ultimately referred» ${ }^{18}$. Está presente tanto en la dedicatoria que encabeza la égloga como en las primeras y últimas estrofas pastoriles. Al mismo tiempo, el paralelo entre la voz poética de Garcilaso y la de Nemoroso que se establecía en la Égloga I se vuelve aquí más estrecho, resaltando la posición privilegiada que han logrado ambos gracias a su arte. Es el agua la que posibilita esta ascensión a una fama eterna, revelándose como la vía por excelencia a través de la cual se difunde la voz órfica de los poetas. Si bien los cantos de Salicio y Albanio no sobrevivirán su muerte corporal, el de Nemoroso transcenderá el espacio temporal del locus amoenus para subir a una esfera de inmortalidad poética ${ }^{19}$.

En algunas de las líneas más célebres de las églogas, la voz poética de Garcilaso jura seguir elogiando a doña María Osorio, esposa del virrey de Nápoles, don Pedro de Toledo, más allá de los límites de su condición humana, afirmando:

[...] con la lengua muerta y fría en la boca pienso mover la voz a ti debida;

libre mi alma de su estrecha roca,

por el Estigio lago conducida,

celebrando t'irá, y aquel sonido

hará parar las aguas del olvido (vv. 11-16).

La muerte simbólica del poeta libera su alma, que es su voz poética20; como la cabeza de Orfeo en su camino por el río Ebro, gritando el nombre de su mujer en un lamento recogido y repetido por el río mismo, los versos de Garcilaso harán eterna la memoria de doña María ${ }^{21}$. De esta manera, Garcilaso se presenta como una

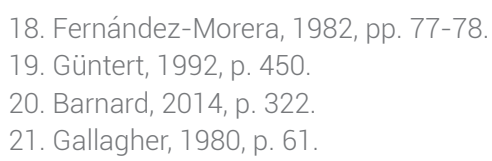


figura órfica cuya voz poética es capaz de frenar el curso de las aguas del olvido, haciéndose escuchar más allá de la muerte ${ }^{22}$.

La función del río como vía hacia la inmortalidad poética en esta dedicatoria tiene un papel análogo dentro del espacio del locus amoenus. Al igual que en las dos primeras églogas, esta última se abre ubicando la escena pastoril dentro de un marco acuático:

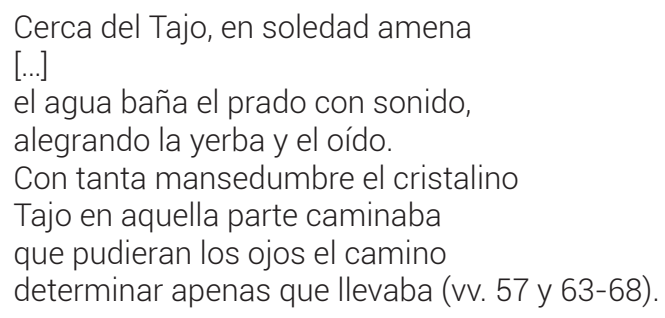

Se ven algunos elementos familiares en estos versos, sobre todo en la descripción visual y auditiva del agua que sigue alegrando la vista y el oído de los pastores con su rumor. No obstante, la perspectiva es otra: se ha dejado de enfatizar su papel de interlocutor y confidente de los pastores para resaltar más bien la forma que el Tajo adquiere al atravesar el locus amoenus ${ }^{23}$. En este sentido, la tercera égloga continúa elaborando el paisaje introducido en la Égloga II, donde se amplía la geografía dentro de la cual se sitúa el espacio pastoril.

Al mismo tiempo, este panorama terrenal se convierte en el escenario de otro tipo de ser: la presencia humana dentro del locus amoenus ha sido reemplazada por la de las ninfas, una de las cuales saca su cabeza fuera del agua para contemplar el prado (vv. 70-73). El agua ya no está al servicio de los pastores en la ribera sino al de las ninfas, que han hecho allí su morada. Por primera vez salen del agua a la vista de los lectores; sus rasgos físicos hacen de ellas no solo residentes del ámbito acuático sino una personificación del mismo ${ }^{24}$ : sus «cabellos d'oro» (v. 69) corresponden a la arena dorada y el «blanco pie» a las blancas piedras al fondo del agua (Égloga II, vv. 446-447). Sus creaciones artísticas también reflejan una relación íntima con su entorno: tal y como el río Tajo representa un hilo que corre por el espacio geográfico-poético de las églogas, así los tapices están compuestos literalmente de hilos, hechos del oro del mismo Tajo, que nos conducen por las narrativas míticas que cuentan ${ }^{25}$.

De esta manera, el agua se convierte en el camino simbólico a través del cual Nemoroso alcanzará una fama poética eterna. A diferencia de los mitos clásicos que las otras ninfas eligen tejer, Nise opta por representar en su tapiz un mito nuevo -el del pastor Nemoroso y Elisa. Haciéndose eco de la estructura de las églogas mismas, para las cuales el agua sirve como marco retórico e hilo narrativo, Nise

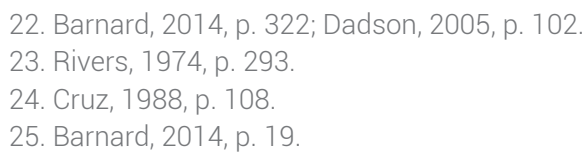


teje su historia amorosa sobre el fondo del Tajo, cuya trayectoria serpentina nos conduce por la historia amorosa del pastor (vv. 197-216). Tan enternecida está por el destino lamentable de los amantes que,

porque aqueste lamentable cuento

no sólo entre las selvas se contase,

mas dentro de las ondas sentimiento

con la noticia desto se mostrase,

quiso que de su tela el argumento

la bella ninfa muerta señalase

y ansí se publicase de uno en uno

por el húmido reino de Neptuno (vv. 257-264).

A diferencia de la vida fugaz que experimentarán las crisis amorosas de Salicio y Albanio, ya que están condenadas a existir solo en la memoria de los pastores mismos, la ninfa difunde el relato de Nemoroso más allá de los confines del locus amoenus y se asegura de que se perpetúe aún después de la muerte del pastor ${ }^{26}$. Son las corrientes del agua las que llevan el nombre de Elisa para que sea escuchado hasta en las profundidades del reino oceánico. No queda duda del papel determinante del agua para inmortalizar el canto de Nemoroso: es una criatura acuática quien recoge la voz poética del pastor, y es la vía metafórica misma que hace llegar la historia a una esfera eterna de la poesía27.

Así, gracias al agua Nemoroso asume definitivamente el papel de Orfeo moderno, cuya historia amorosa será conmemorada para siempre. Logra unirse a los otros que, a su vez, han conseguido la inmortalidad poética y le han servido como modelos a lo largo de las églogas -el mago Severo y el poeta Garcilaso. El éxito de Nemoroso de hacerse escuchar, no solo dentro del locus amoenus sino también lejos de allí, contrasta con el destino de los cantos de Albanio y Salicio. Ninguno logra que su voz se libere del espacio del locus amoenus ni de su condición humana; sus historias amorosas, y también ellos mismos, quedarán firmemente ancladas en el mundo pastoril que les da sentido a sus vidas. El agua, fuente de la vida terrenal y mítica, es tal vez la mayor protagonista de las tres églogas, tanto por lo que les ofrece a los pastores que acuden a la ribera como por lo que les niega. Las voces de los pastores, sus amantes e incluso Garcilaso mismo se articulan desde ese río que es el único camino hacia la fama poética.

La presencia de estas figuras órficas modernas en las églogas también se puede entender como comentario de la superioridad de lo moderno sobre lo antiguo. No es coincidencia que el tapiz de Filódoce muestre al músico griego tras la pérdida de su esposa, quejándose «al monte solitario en vano», una escena que recuerda a los lamentos de Albanio que quedan sin ninguna respuesta (v. 144). A diferencia del poder que Severo, Nemoroso y el mismo Garcilaso tienen de dominar los elementos naturales con su canto poético, la música del Orfeo griego ha perdido su 
hechizo ${ }^{28}$. Si bien Garcilaso presenta al músico griego como un prototipo clásico ${ }^{29}$, en estas églogas lo moderno ha conseguido reemplazar a lo antiguo. El Orfeo de la mitología clásica ya no es un modelo que haya que emular sino superar. Los únicos que ejercen el poder sobre la palabra son el poeta español y los personajes de su creación literaria.

\section{BiBLIOGRAFÍA}

Araya, Guillermo, «La fuente y los ríos en Garcilaso», Estudios filológicos, 6, 1970, pp. 113-134.

Arce de Vázquez, Margot, «La Égloga primera de Garcilaso», La torre, 1.2, 1953, pp. 31-68.

Barnard, Mary E., «Garcilaso's Poetics of Subversion and the Orpheus Tapestry», PMLA, 102.3, 1987, pp. 316-325.

Barnard, Mary E., Garcilaso de la Vega and the Material Culture of Renaissance Europe, Toronto, University of Toronto Press, 2014.

Braschi, Giannina, «Metamorfosis del ingenio en la Égloga III de Garcilaso», Revista Canadiense de Estudios Hispánicos, 4.1, 1979, pp. 19-36.

Correa, Gustavo, «Garcilaso y la mitología», Hispanic Review, 45.3, 1977, pp. 269-281.

Covarrubias Orozco, Sebastián de, Tesoro de la lengua castellana o española, ed. Felipe C. R. Maldonado, Madrid, Castalia, 1994.

Cruz, Anne, Imitación y transformación. El petrarquismo en la poesía de Boscán y Garcilaso de la Vega, Philadelphia, J. Benjamins Publishing Company, 1988.

Curtius, Ernst Robert, European Literature and the Latin Middle Ages, Princeton University Press, 1983 [1953].

Dadson, Trevor J., «From Voice to Silence: Orpheus and the Epitaph in Garcilaso and Camões», Portuguese Studies, 21, 2005, pp. 101-111.

Fernández-Morera, Darío, The Lyre and the Oaten Flute: Garcilaso and the Pastoral, London, Tamesis Books Limited, 1982.

Gallagher, Patrick, «Locus Amoenus: The Aesthetic Centre of Garcilaso's Third Eclogue», en Hispanic Studies in Honor of Frank Pierce, ed. John England, Sheffield, University of Sheffield, 1980, pp. 59-75.

García Galiano, Ángel, «Relectura de la Égloga II», Revista de Literatura, LXII, 2000, pp. 20-40. 
Güntert, Georges, «Garcilaso, Égloga primera: la adopción de la distancia estética», en Actas del X Congreso de la Asociación Internacional de Hispanistas: Barcelona, 21-26 de agosto de 1989, Barcelona, Promociones y Publicaciones Universitarias, 1992, pp. 443-455.

MacDonald, Ines, «La Égloga II de Garcilaso», en La poesía de Garcilaso. Ensayos críticos, ed. Elias L. Rivers, Barcelona, Ariel, 1974, pp. 211-235.

Navarrete, Ignacio, Orphans of Petrarch: Poetry and Theory in the Spanish Renaissance, Berkeley, University of California Press, 1994.

Parker, Alexander A., «Tema e imagen en la Égloga I de Garcilaso», en La poesía de Garcilaso. Ensayos críticos, ed. Elias L. Rivers, Barcelona, Ariel, 1974, pp. 199-208.

Rivers, Elias L., «La paradoja pastoril del arte natural», en La poesía de Garcilaso. Ensayos críticos, ed. Elias L. Rivers, Barcelona, Ariel, 1974, pp. 287-308.

Torres, Isabel, «Sites of Speculation: Water/Mirror Poetics in Garcilaso de la Vega's Eclogue Il», Bulletin of Hispanic Studies, 86.6, 2009, pp. 877-892.

Vega, Garcilaso de la, Obras completas con comentario, ed. Elias L. Rivers, Madrid, Castalia, 2001.

Wescott, Howard B., «Nemoroso's Odyssey: Garcilaso's Eclogues Revisited», Hispania, 78.3, 1995, pp. 474-482. 